\title{
Sound production by the West Australian dhufish (Glaucosoma hebraicum)
}

\author{
Miles J. G. Parsons ${ }^{\text {a) }}$ \\ Centre for Marine Science and Technology, Curtin University, GPO Box U1987, Perth, WA 6845, Australia \\ Simon Longbottom \\ Curtin Aquaculture Research Laboratory, Curtin University, GPO Box U1987, Perth, WA 6845, Australia \\ Paul Lewis \\ Department of Fisheries, Government of Western Australia, PO Box 20, North Beach, WA 6020, Australia \\ Robert D. McCauley \\ Centre for Marine Science and Technology, Curtin University, GPO Box U1987, Perth, WA 6845, Australia \\ David V. Fairclough \\ Department of Fisheries, Government of Western Australia, PO Box 20, North Beach, WA 6020, Australia
}

(Received 31 July 2012; revised 22 June 2013; accepted 5 August 2013)

\begin{abstract}
Biological examinations of Glaucosomatid fish species have suggested that they could produce sound via swimbladder vibration, using "sonic" muscles. However, there have been few reported instances of it in the family. West Australian dhufish (Glaucosoma hebraicum) is an iconic teleost, endemic to Western Australia. Dissection of G. hebraicum in this study identified the presence of "sonic" muscle pairs in immature and sexually mature individuals. The muscle tissue originates in the otic region of the skull with its insertion at the anterior of the swimbladder. Recordings of sounds were acquired from two male G. hebraicum, at a range of $1 \mathrm{~m}$, during capture. Calls comprised 1 to 14 swimbladder pulses with spectral peak frequency of $154 \pm 45 \mathrm{~Hz}(n=67$ calls) and $3 \mathrm{~dB}$ bandwidth of $110 \pm 50 \mathrm{~Hz}$. The mean of all call maximum source levels was $126 \mathrm{~dB}$ re $1 \mu \mathrm{Pa}$ at $1 \mathrm{~m}$ with the highest level at $137 \mathrm{~dB}$ re $1 \mu \mathrm{Pa}$ at $1 \mathrm{~m}$. The confirmation of sound production by G. hebraicum and the acoustic characteristics of those sounds could be used to gain a better understanding of its ecology and, particularly, whether the production of sound is associated with specific behaviors, such as reproduction.
\end{abstract}

(C) 2013 Acoustical Society of America. [http://dx.doi.org/10.1121/1.4818775]

PACS number(s): 43.30.Sf, 43.80.Ka, 43.64.Tk [MCH]

Pages: $2701-2709$

\section{INTRODUCTION}

Over 800 species of fish are known to produce sound via a number of different evolved mechanisms (Kaatz, 2002). Their sounds are often associated with a particular behavior, such as spawning, feeding, or disturbance (Winn, 1964; Myrberg and Spires, 1972; Fine et al., 1977; Slabbekoorn et al., 2010). As sound propagates efficiently underwater (Urick, 1983), recordings of fish calls can offer an effective means of determining natural fish behavior and provide valuable information on the location and timing of associated behavior (Gannon, 2008;, Rountree et al., 2006). Of particular note is the formation of spawning aggregations. Such information could be relevant to management when making decisions about the respective locations and timing of spatial or temporal closures to fishing for vulnerable species. The use of sound as a research tool for determining such behavior is particularly advantageous under certain circumstances, e.g., in conditions of low visibility (turbid waters and/or low light levels) or for shy species (Mackie et al., 2009), when other sampling techniques are less successful. However, it is first necessary to have an

\footnotetext{
a) Author to whom correspondence should be addressed. Electronic mail: m.parsons@cmst.curtin.edu.au
}

understanding of the acoustic features of a species' calls and how they are produced (e.g., swimbladder vibration or stridulation), to determine how best to characterize them.

The West Australian dhufish (Glaucosoma hebraicum; Glaucosomatidae) is an iconic and heavily targeted species that is endemic to coastal waters of Western Australia (Fig. 1; McKay, 1997; St John and Syers; 2005; Wise et al., 2007). It is a slow growing, sedentary, demersal species inhabiting reefs and caves to depths of $200 \mathrm{~m}$ (Hutchins and Swainston, 1986; St John and Syers, 2005; Hesp et al., 2002). G. hebraicum is a large species which reaches $1.22 \mathrm{~m}$ total length and $26 \mathrm{~kg}$, and matures at approximately $25 \%$ of maximum length (Hutchins and Swainston, 1986; Hesp et al., 2002; Mackie et al., 2009). G. hebraicum display little variation in reproductive seasonality along the west coast between Augusta and Kalbarri, with ovarian development commencing as water temperatures begin to increase from their annual low, rather than in relation to a latitudinal gradient, and spawning occurring predominantly in austral summer/autumn (Hesp et al., 2002; St John and Syers, 2005; Lenanton et al., 2009; Mackie et al., 2009). Males have been recorded as co-inhabiting small areas during spawning periods, often with a dominant male displaying a larger dorsal filament than other males, indicating they may exhibit lekking behavior (Mackie et al., 2009; Hauser, 1996). At spawning 


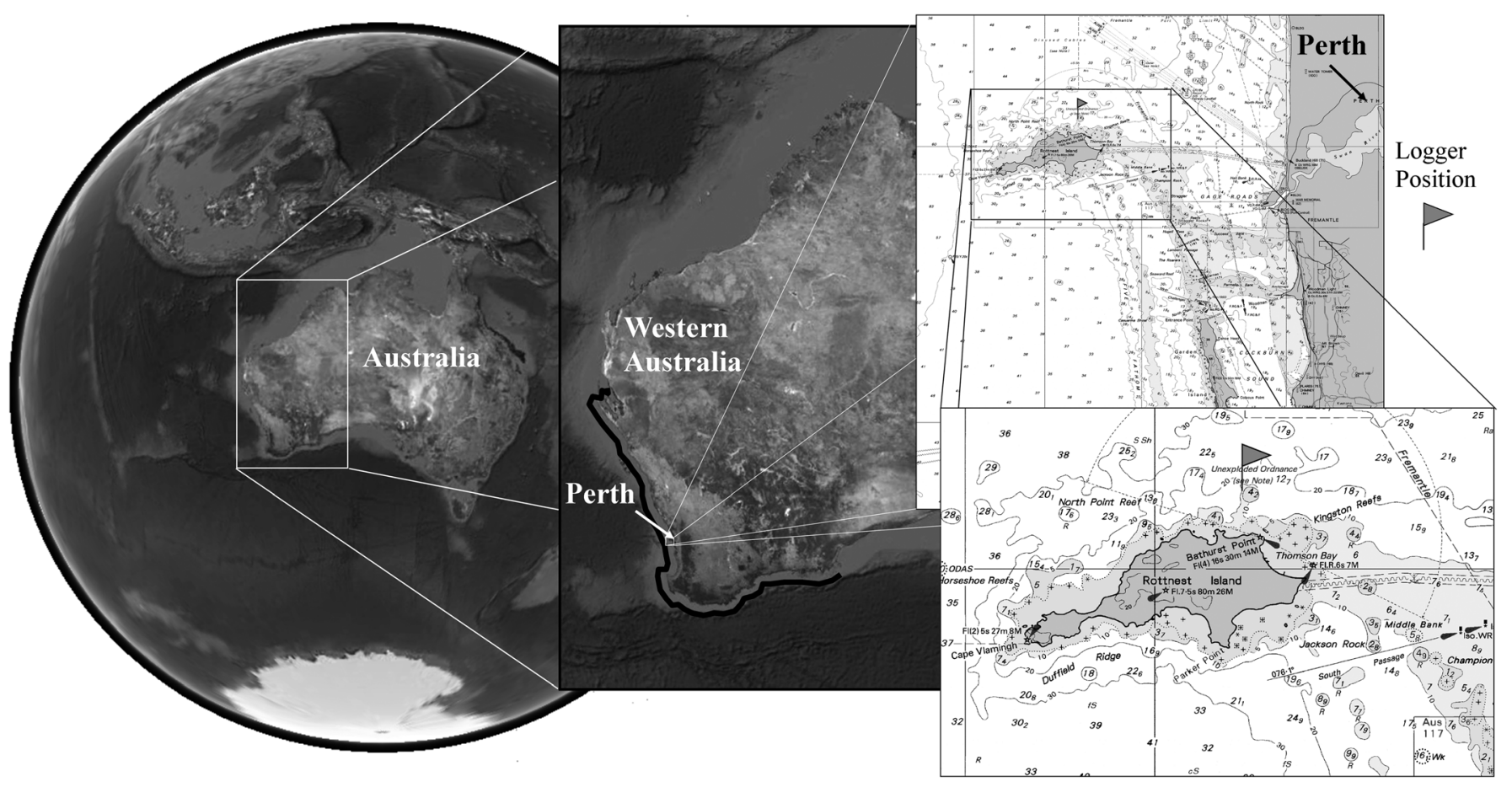

FIG. 1. Map of Western Australia with a magnification of Rottnest Island. Distribution of G. hebraicum in WA shown by black line.

times, groups of up to three fish are typical, up to ten fish to a lesser extent, and occasionally tens or hundreds of fish, have been reported (Mackie et al., 2009). Males have small testes relative to other gonochoristic species, which implies they are likely to exhibit pair spawning behavior. Furthermore, spawning frequency has a positive relationship with size and the larger males are thought to spawn most frequently with the largest females (St John and Syers, 2005). Together, these facts indicate that social cues, such as visual or acoustic cues, may be important during spawning. Mackie et al. (2009) also suggested that vocalization may be a form of communication in this species.

Chiu et al. (2006) reported that biochemical assessment of elevated levels of citrate synthase and L-lactate dehydrogenase (enzymes associated with energy supply for muscle contraction) in swimbladder muscles of the pearl perch (Glaucosoma buergeri) suggested the ability of the muscle to act as a "super-fast" twitch muscle (Rome, 2005). This muscle may be involved in sound production. Mok et al. (2011) detailed the mechanism for sound production in G. buergeri demonstrating that the "sonic" muscles could vibrate two different chambers within the swimbladder.

This study tested the hypothesis that, like its congener $G$. buergeri, $G$. hebraicum contains the physical mechanisms to produce sound. Once confirmed, direct field recordings were acquired of $G$. hebraicum calls to describe the acoustic characteristics of the calls, including source levels (SLs) and the behaviors with which those calls may be associated.

\section{METHODS}

Six adults (purchased or donated to Curtin University) and two juvenile $G$. hebraicum were dissected (the latter as part of a Department of Fisheries research project). The total length and sex of each fish were recorded. Examinations were conducted to identify the presence and location of potential sonic muscles used in sound production similar to those in G. buergeri (Chiu et al., 2006) and determine whether such muscles were present in sexually immature and mature individuals (Fig. 2).

On 13 December 2011, sound recordings of two $G$. hebraicum, captured using rod and line in $14 \mathrm{~m}$ of water near Rottnest Island (Fig. 1; approximately E115 $30^{\prime}, \mathrm{S} 32^{\circ} 0^{\prime}$ ), were made using calibrated, omni-directional, HTI 90-U and 96-min hydrophones (HighTech Inc., Long Beach, MS). The 90-U hydrophone was attached to an autonomous sea-noise logger developed at Curtin University, Western Australia and the Defense Science and Technology Organisation, sampling for five of every seven minutes at a rate of $11 \mathrm{kHz}$. The HTI-min hydrophone was attached to an HR-5 "Jamminpro" recorder sampling continuously at $16 \mathrm{kHz}$. The fish were raised to the surface over a period of $10 \mathrm{~min}$ to limit swimbladder expansion, during which time a hydrophone (HTI 96-min) was located approximately $1 \mathrm{~m}$ from the fish. In each case, a snorkeler at the water's surface capable of free-diving to the seafloor ensured the range between fish and hydrophone was kept as close to $1 \mathrm{~m}$ as possible.

The fish was briefly removed from the water so the sex could be determined from the presence/absence of a dorsal fin filament, which is only present in males (Mackie et al., 2009), and the total length was measured to the nearest $1 \mathrm{~mm}$. Each fish was then rapidly returned to the seabed using a release weight, attached to the fishing line, which reduces the effects of barotrauma (Bartholomew and Bohnsack, 2005). The release weight comprises a weighted, barbless hook which is passed through the upper jaw, from above, so that the hook points downward. The weight and fish are lowered to the desired depth, whereby a sharp tug on 
a

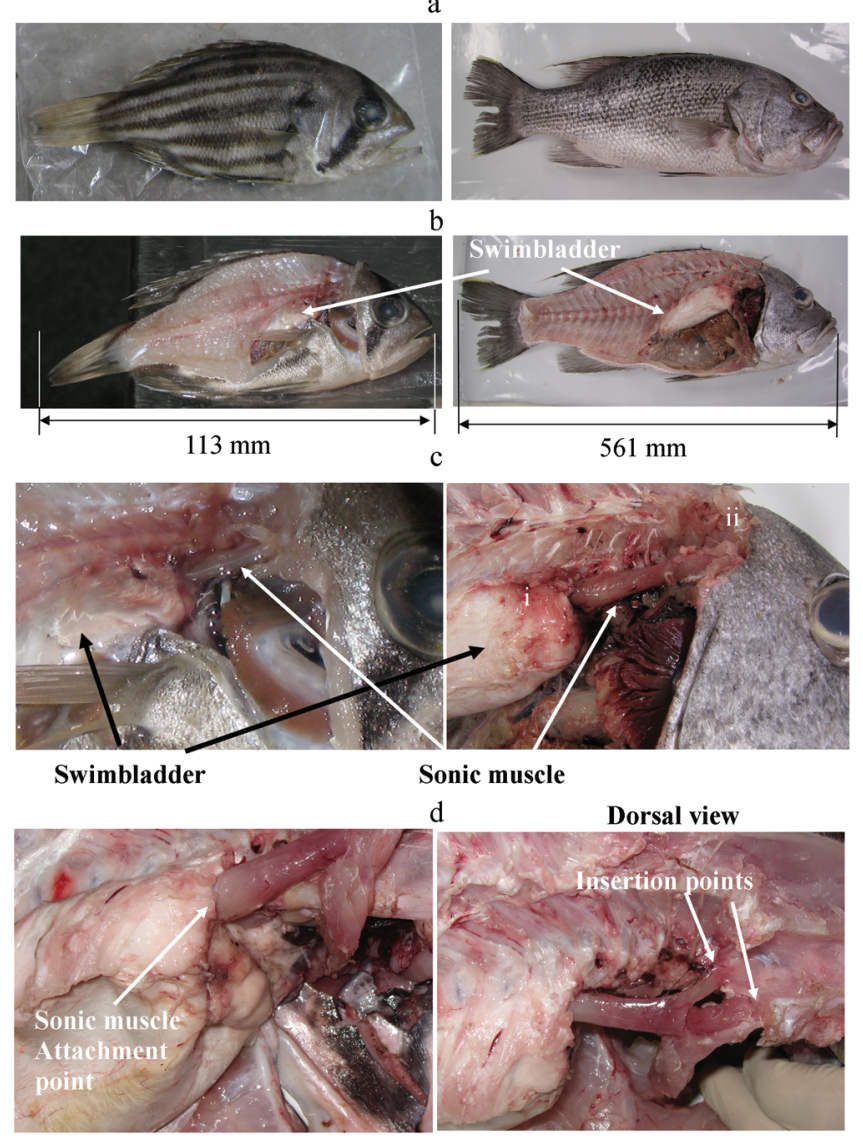

FIG. 2. (a) Whole and (b) dissected $113 \mathrm{~mm}$ (left images) and $425 \mathrm{~mm}$ (right images) male $G$. hebraicum. Magnification of likely sonic muscles connected at the anterior of the swimbladder (i) and posterior of either side of the brain case (ii) are shown (c). Structure of adult sonic muscle and vascularized muscle are highlighted. (d) Lateral view of sonic muscle attachment to swimbladder (left) and dorsal view of sonic muscle separating to two insertion points around the otic region of the brain casing (right) in the adult G. hebraicum.

the line releases the fish. The release weight is then retrieved. During the release, the Centre for Marine Science and Technology (CMST) logger (HTI 90-U) was simultaneously deployed to the seabed, as close as possible to $1 \mathrm{~m}$ from the fish. Once again, a free-diving snorkeler maintained the range between hydrophone and fish.

Removal of background noise and call energy level analyses were conducted using methods outlined in McCauley (2001) and Parsons et al. (2012) with a suite of MATLAB programs developed at the CMST, including the characterisation of recorded underwater sounds (CHORUS) toolbox. Spectrograms were produced using either a 1024- or 256-sample Hanning window. Spectral peak frequency of each call and pulse was determined from power spectral density plots. For comparison, the durations of the first and second cycles of each pulse and the pulse duration were determined from the waveforms of numerous calls, as per Connaughton et al. (2000). The frequencies of each cycle and the total duration were then compared to that of the spectral peak frequency of the equivalent pulse.

Where recordings were taken at a range of $1 \mathrm{~m}$, the transmission loss was $0 \mathrm{~dB}$ and therefore received levels (RL) and SL were effectively the same. However, maintaining a range of $1 \mathrm{~m}$ between a fish on a line and a hydrophone was nontrivial. Three standard deviations in the distribution of ranges at which recordings were taken have been estimated at $0.5 \mathrm{~m}$ to provide maximum and minimum limits in the possible SL of each recorded call. For each maximum and minimum, the transmission loss between fish and hydrophone was assumed to be equal to spherical spreading (Cato, 1998). The RLs were measured for all calls from time-averaged power spectrum densities over the $50 \mathrm{~Hz}$ to $750 \mathrm{~Hz}$ bandwidth. Mean levels and confidence limits were calculated in the linear domain.

Similar to Parsons et al. (2012), the call SLs are presented in three formats to aid comparison of the results reported here with other past and future results. SLs have been quoted in sound pressure level (SPL; dB re $1 \mu \mathrm{Pa}$ at $1 \mathrm{~m}$ ), sound exposure level (SEL; $\mathrm{dB}$ re $1 \mu \mathrm{Pa} 2 \mathrm{~s}$ at $1 \mathrm{~m}$ ), and peak-peak pressure (Pa) as defined in Southall et al. (2007).

\section{RESULTS}

Dissections revealed that in each adult and juvenile G. hebraicum, the swimbladder was located at the posterior end of the abdominal cavity, approximately halfway along the body [Figs. 2(a) and 2(b)]. Bi-lateral sonic muscles (Chiu et al., 2006; Mok et al., 2011), were observed in all examined individuals (Fig. 2). These muscles had the same characteristics as Baudelot's ligament, originating in the otic region of the skull, either side of the posterior part of the brain casing, near the otoliths [Fig. 2(c), mark ii]. Two insertion points were observed [Fig. 2(d), right image] before the muscle joined, forming one striated muscle which extended posteriorly to insert at the anterior of the swimbladder [Figs. 2(c), mark i and 2(d), left image]. The sonic muscles were the only muscles observed to be attached to the swimbladder. In the adult $G$. hebraicum (range of 32.5-56.1 cm total length), these muscles were striated, highly vascularized, and deep red in color, while in the 11 and $13 \mathrm{~cm}$ juveniles, the muscles were striated, but white.

The two G. hebraicum captured in the field were male and were 45 and $32 \mathrm{~cm}$ total length and considered likely to be sexually mature, based on comparison with the length at sexual maturity $\left(L_{50}\right)$ of males of this species (Hesp et al., 2002). Both captured individuals produced sounds while being raised to the surface and when lowered back to the seafloor (see Table I for acoustic characteristics). When the fish was close to the surface or handled, vibrations of the body were visibly detectable at the same time as these sounds were being produced, confirming the G. hebraicum as the sound source.

The mean of call maximum root-mean-square (rms) SLs of the two fish was $126 \mathrm{~dB}$ re $1 \mu \mathrm{Pa}(n=67$, max $=137$, min$=113$ ) with upper and lower confidence limits of 130 and $116 \mathrm{~dB}$ re $1 \mu \mathrm{Pa}$, respectively. Separately, the mean of the maximum SLs of calls from the first $(45 \mathrm{~cm}, n=13)$ and second $(32 \mathrm{~cm}, n=54)$ fish were 128 and $125 \mathrm{~dB}$ re $1 \mu \mathrm{Pa}$, respectively (Table I). The mean of the call maximum SELs for both fish together, the $45 \mathrm{~cm}$ fish, and the $32 \mathrm{~cm}$ fish were 117,110 , and $118 \mathrm{~dB}$ re $1 \mu \mathrm{Pa}^{2} \mathrm{~s}$, respectively. The difference between upper and lower confidence limits for the rms SL was 8 and $17 \mathrm{~dB}$ re $1 \mu \mathrm{Pa}$ for the first and second fish, 


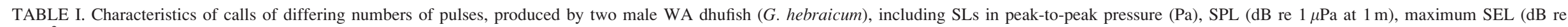

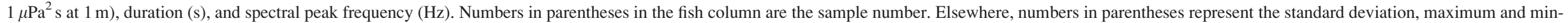
imum values.

\begin{tabular}{|c|c|c|c|c|c|c|}
\hline Call type & Fish $(n)$ & Peak-peak pressure $(\mathrm{Pa})$ & Maximum SL (dB re $1 \mu \mathrm{Pa}$ ) & Maximum SEL (dB re $1 \mu \mathrm{Pa}^{2} \mathrm{~s}$ ) & Call duration (s) & Spectral peak frequency $(\mathrm{Hz})$ \\
\hline \multirow[t]{3}{*}{ All calls } & All (67) & $10.8( \pm 7.4,35.2,2.3)$ & $126(130,116,137,113)$ & $117(122,109,126,97)$ & $0.38( \pm 0.37,2.6,0.01)$ & $154( \pm 43.5,251,82)$ \\
\hline & $1(13)$ & $0.39( \pm 0.29,0.85,0.05)$ & $128(131,123,133,122)$ & $110(113,104,117,97)$ & $0.39( \pm 0.29,0.85,0.05)$ & $144( \pm 38,199,95)$ \\
\hline & $2(54)$ & $0.38( \pm 0.39,2.6,0.02)$ & $125(130,113,137,113)$ & $118(122,112,126,108)$ & $0.38( \pm 0.39,2.6,0.02)$ & $157( \pm 45,250,82)$ \\
\hline \multirow[t]{2}{*}{1 Pulse } & $1(0)$ & $\mathrm{n} / \mathrm{a}$ & $\mathrm{n} / \mathrm{a}$ & $\mathrm{n} / \mathrm{a}$ & $\mathrm{n} / \mathrm{a}$ & $\mathrm{n} / \mathrm{a}$ \\
\hline & $2(9)$ & $15( \pm 9.3,28.3,5.4)$ & $128(133,119,133,115)$ & $120(124,113,124,112)$ & $0.11( \pm 0.12,0.39,0.08)$ & $148( \pm 45,220,98)$ \\
\hline \multirow[t]{2}{*}{2 Pulse } & $1(3)$ & $6.13( \pm 3.5,9.2,2.3)$ & $130(134,123,134,122)$ & $108(113,97,113,98)$ & $0.11( \pm 0.06,0.15,0.05)$ & $113( \pm 15.6,122,95)$ \\
\hline & $2(16)$ & $11.4( \pm 9.2,35.2,4.9)$ & $125(130,121,137,115)$ & $118(122,112,126,113)$ & $0.21( \pm 0.07,0.38,0.13)$ & $161( \pm 42,221,97)$ \\
\hline \multirow[t]{2}{*}{3 Pulse } & $1(5)$ & $5.3( \pm 2.4,9.0,3.6)$ & $129(132,125,132,125)$ & $112(115,106,117,108)$ & $0.38( \pm 0.26,0.75,0.17)$ & $170( \pm 32,193,121)$ \\
\hline & $2(9)$ & $12.2( \pm 5.3,20.1,6.8)$ & $125(129,117,131,117)$ & $119(122,114,123115)$ & $0.26( \pm 0.05,0.35,0.20)$ & $157( \pm 37,217,103)$ \\
\hline \multirow[t]{2}{*}{4 Pulse } & $1(0)$ & $\mathrm{n} / \mathrm{a}$ & $\mathrm{n} / \mathrm{a}$ & $\mathrm{n} / \mathrm{a}$ & $\mathrm{n} / \mathrm{a}$ & $\mathrm{n} / \mathrm{a}$ \\
\hline & $2(6)$ & $14.7( \pm 6.8,21.2,4.5)$ & $128(131,121,132,119)$ & $120(123,113,123,110)$ & $0.43( \pm 0.08,0.55,0.35)$ & $198(52,251,117)$ \\
\hline \multirow[t]{2}{*}{5 Pulse } & $1(3)$ & $4.5( \pm 0.9,5.4,3.6)$ & $127(127,126,127,126)$ & $109(111,106,111,107)$ & $0.54( \pm 0.35,0.79,0.14)$ & $148( \pm 48,199,103)$ \\
\hline & $2(6)$ & $7.8( \pm 2.7,12.6,4.7)$ & $120(123,113,125,113)$ & $114(116,110,116,110)$ & $0.57( \pm 0.17,0.93,0.46)$ & $134( \pm 22,166,107)$ \\
\hline \multirow[t]{2}{*}{6 Pulse } & $1(0)$ & 3.1 & 123 & 115 & 0.79 & 156 \\
\hline & $2(6)$ & $10.4( \pm 4.8,14.6,4.8)$ & $124(128,116,130,116)$ & $118(122,112,123,111)$ & $0.65( \pm 0.13,0.81,0.51)$ & $159( \pm 41,205,127)$ \\
\hline \multirow[t]{2}{*}{7 Pulse } & $1(1)$ & 2.5 & 122 & 108 & 0.85 & 141 \\
\hline & $2(0)$ & $\mathrm{n} / \mathrm{a}$ & $\mathrm{n} / \mathrm{a}$ & $\mathrm{n} / \mathrm{a}$ & $\mathrm{n} / \mathrm{a}$ & $\mathrm{n} / \mathrm{a}$ \\
\hline \multirow[t]{2}{*}{8 Pulse } & $1(0)$ & $\mathrm{n} / \mathrm{a}$ & $\mathrm{n} / \mathrm{a}$ & $\mathrm{n} / \mathrm{a}$ & $\mathrm{n} / \mathrm{a}$ & $\mathrm{n} / \mathrm{a}$ \\
\hline & $2(0)$ & 20.6 & 126 & 123 & 0.75 & 237 \\
\hline \multirow[t]{2}{*}{9 Pulse } & $1(0)$ & $\mathrm{n} / \mathrm{a}$ & $\mathrm{n} / \mathrm{a}$ & $\mathrm{n} / \mathrm{a}$ & $\mathrm{n} / \mathrm{a}$ & $\mathrm{n} / \mathrm{a}$ \\
\hline & $2(0)$ & 10 & 120 & 118 & 1.3 & 82 \\
\hline \multirow[t]{2}{*}{14 Pulse } & $1(0)$ & $\mathrm{n} / \mathrm{a}$ & $\mathrm{n} / \mathrm{a}$ & $\mathrm{n} / \mathrm{a}$ & $\mathrm{n} / \mathrm{a}$ & $\mathrm{n} / \mathrm{a}$ \\
\hline & $2(0)$ & 11.2 & 117 & 111 & 2.6 & 102 \\
\hline
\end{tabular}




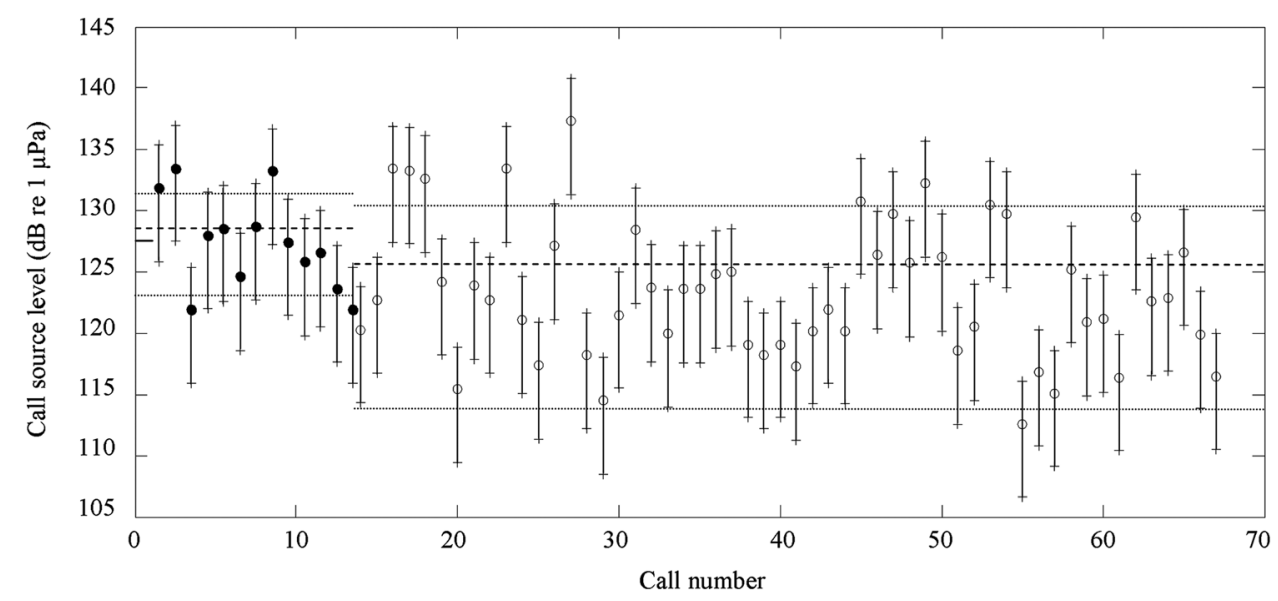

FIG. 3. Residual SPLs around the relationship between SL and pulse number plotted against the number of pulses in each call for the 45 (filled circles) and 32 (empty circles) $\mathrm{cm} \mathrm{G}$. hebraicum. Error bars show the maximum and minimum possible SLs assuming $0 . \mathrm{m}$ as three standard deviations in the range between fish and hydrophone for each call. The mean SL for each fish is shown by the dashed line and the $95 \%$ confidence limits shown by the dotted lines (calculated in the linear domain).

respectively, and 9 and $10 \mathrm{~dB}$ re $1 \mu \mathrm{Pa}^{2}$ s for the SEL confidence limits, respectively (Fig. 3). The ranges between maximum and minimum rms SL estimates were 11 and $24 \mathrm{~dB}$ re $1 \mu \mathrm{Pa}$ for the first and second fish, respectively, and the same values for SELs were 20 and $18 \mathrm{~dB}$ re $1 \mu \mathrm{Pa}^{2}$ s, respectively (Table I, Fig. 4). If these extreme ranges in SLs were due to maximum differences in distance between fish and hydrophone (i.e., recordings of highest estimated SL were actually taken at $0.5 \mathrm{~m}$ and those of the lowest taken at $1.5 \mathrm{~m}$ ), the range in rms SL for each fish could have been as low as 2 and $15 \mathrm{~dB}$ re $1 \mu \mathrm{Pa}$ and in SELs, 11 and $9 \mathrm{~dB}$ re $1 \mu \mathrm{Pa}^{2} \mathrm{~s}$ (Table I, Fig. 3).

Similar to the estimated SLs, the distribution of spectral peak frequencies were also broad (Fig. 4) and while the call SLs of the larger, first fish, were higher than that of the second fish overall, the spectral peak frequencies were lower. The mean spectral peak frequency over all calls was $154 \mathrm{~Hz}$ $( \pm 43.5, \max =251, \min =82)$ with a mean $3 \mathrm{~dB}$ bandwidth of $110 \mathrm{~Hz}$ (see Fig. 5 for spectrograms and waveforms of example calls). For the 45 and $32 \mathrm{~cm}$ fish, this frequency was 144 and $157 \mathrm{~Hz}$, respectively. In each call, bands of energy were also observed at frequencies above the spectral peak, similar to those in Figs. 5 and 6, at approximately 350 and $450 \mathrm{~Hz}$.

The duration of cycles in the waveforms of 44 pulses from 15 calls of the second fish were compared to the spectral peak frequency of the respective pulse. In each case, the frequency of the first cycle was similar to that of the second cycle with an average difference of $13 \mathrm{~Hz}$ (approximately $6 \%$ of the cycle frequency). The frequency of both first and second cycles related closely to the spectral peak frequency of the respective pulse (Fig. 7).

Although calls contained between 1 and 14 pulses, 2 pulses were most common (Table I). For calls from both fish, the mean of maximum rms SLs and SELs decreased with calls of an increasing number of pulses (Fig. 8). This decrease was similar for both fish and appeared to be more prominent in the rms SL than the SEL (compare Fig. 8, left with Fig. 8 , right).

\section{DISCUSSION}

This study has investigated the capability of G. hebraicum to produce sound, by determining the biological mechanisms and the recording of sounds produced by individuals during capture. Dissections identified the presence of sonic muscles in adults of both sexes and in juveniles. The majority of soniferous fish species produce sound associated with spawning behavior, which may also be the case for G. hebriacum. However, the fact that adults produced sound during capture also indicates that individuals may make sound when distressed. Furthermore, similar sounds to those reported here have been heard by the authors while observing juveniles underwater, which may also indicate their use as a warning signal.

The reported SLs of $126 \mathrm{~dB}$ re $1 \mu \mathrm{Pa}$ at $1 \mathrm{~m}$ for G. hebraicum are lower than that of silver perch (Bairdiella chrysoura; $135 \mathrm{~dB}$ re $1 \mu \mathrm{Pa}$ at $1 \mathrm{~m}$; Sprague and Luczkovich, 2004) and Oyster toadfish (Opsanus tau; $132 \mathrm{~dB}$ re $1 \mu \mathrm{Pa}$ at $1 \mathrm{~m}$; Barimo and Fine, 1998). Therefore, despite the large

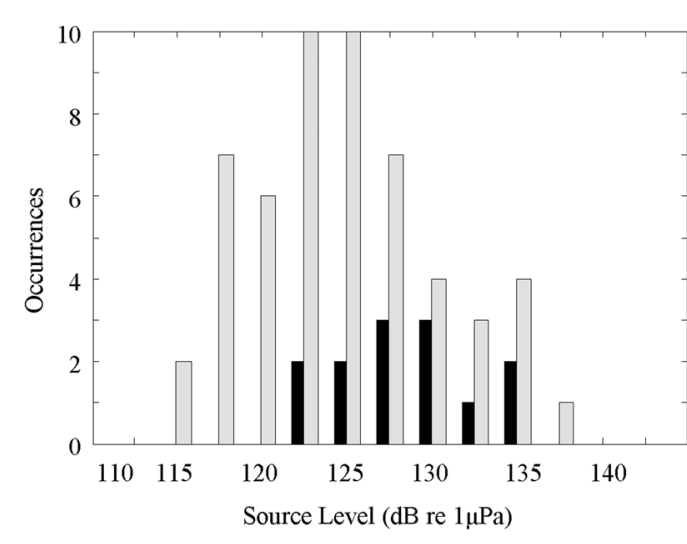

J. Acoust. Soc. Am., Vol. 134, No. 4, October 2013

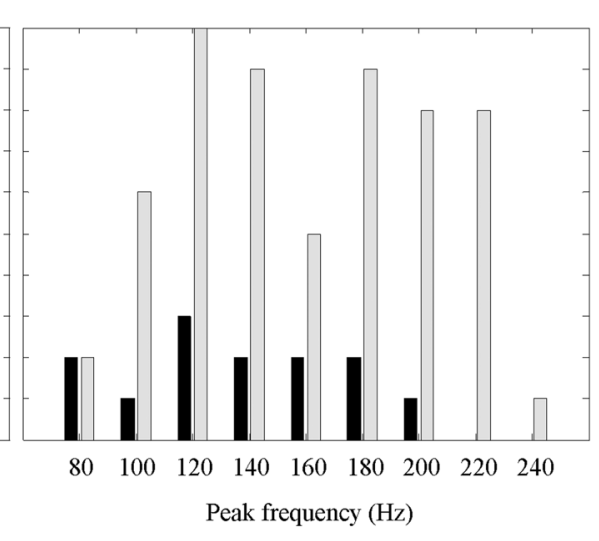

FIG. 4. Distribution of maximum SLs (left) and spectral peak frequencies (right) of all calls from the 45 (black bars) and 32 (gray bars) $\mathrm{cm}$ G. hebraicum. 

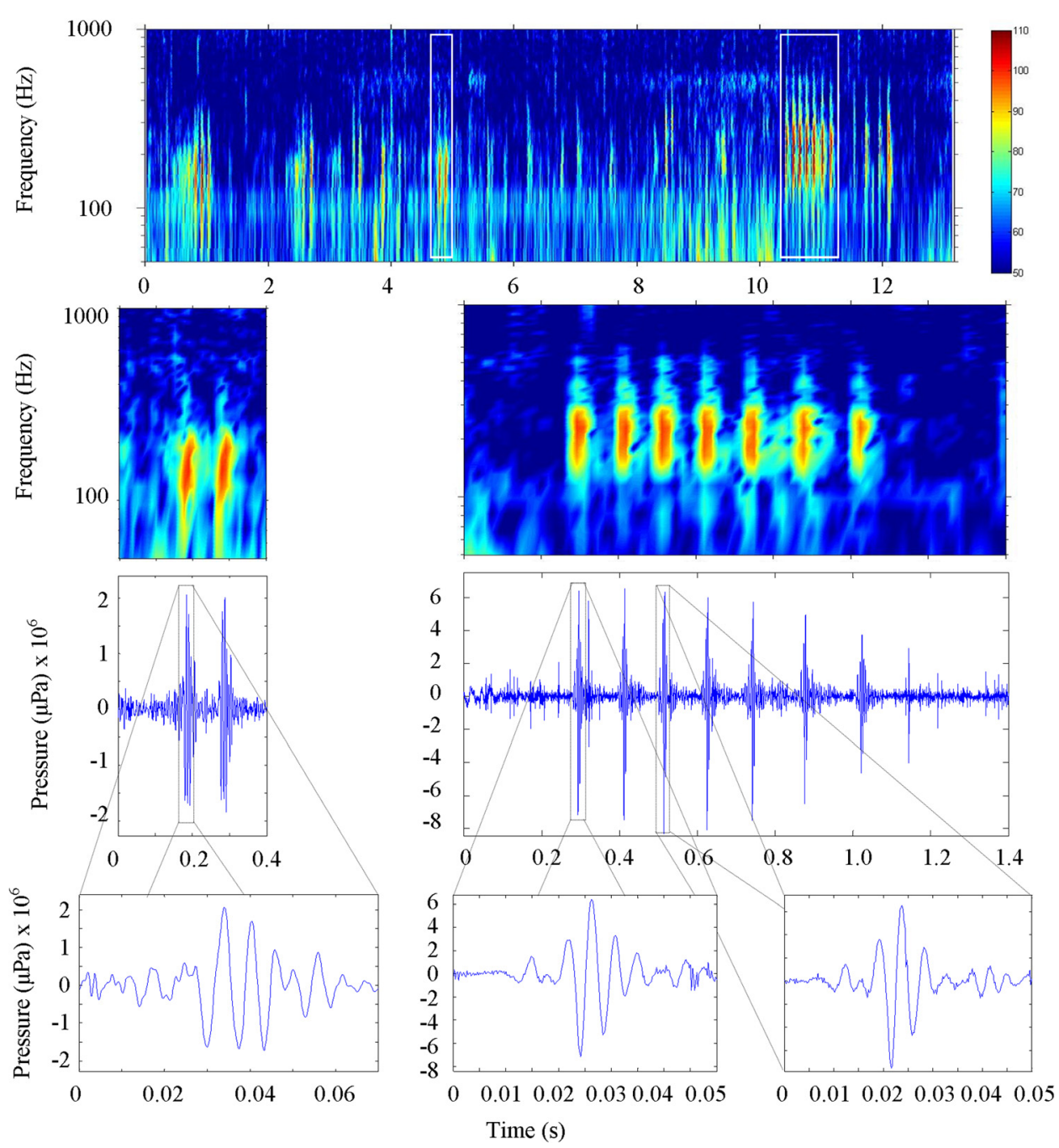

body size of $G$. hebraicum, their calls are of comparatively low level and are of similar intensity to those of the above smaller species. This is most likely due to the different method of sound production which appears to be specific to the Glaucosomatid family (Mok et al., 2011). Large sciaenids, such as mulloway (Argyrosomus japonicus) or black jewfish (Protonibea diacanthus), whose reported maximum

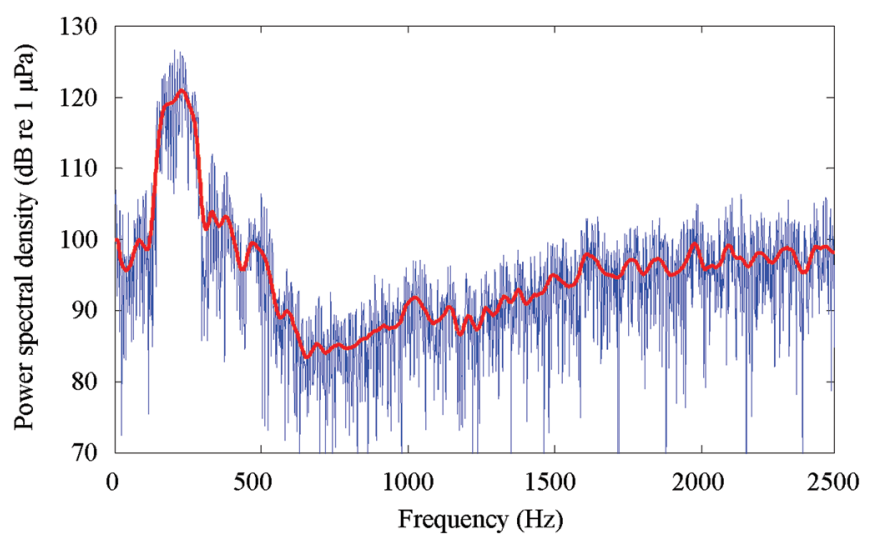

FIG. 6. Power spectral density for the seven pulse G. hebraicum call shown in Fig. 5. Frequency resolution of $2 \mathrm{~Hz}$ (blue line) and $20 \mathrm{~Hz}$ (red line) are shown, highlighting the main band of energy between approximately 125 and $300 \mathrm{~Hz}$, with energy bands at around 350 and $450 \mathrm{~Hz}$.
FIG. 5. (Color online) Spectrogram of a recording taken off Rottnest Island, including two example G. hebraicum calls, comprising two (left magnified call) and seven (right magnified call) swimbladder pulses. Frequency resolution in each spectrogram is $15 \mathrm{~Hz}$. Waveforms of each call are shown with the waveform from individual pulses from each call shown. lengths are 1.81 and $1.50 \mathrm{~m}$, respectively (Sasaki, 2001; Silberschneider et al., 2009), can produce calls of mean SL over 150 and up to $172 \mathrm{~dB}$ re $1 \mu \mathrm{Pa}$ at $1 \mathrm{~m}$ (Cato, 1980; McCauley, 2001; Parsons, 2010; Locascio and Mann, 2011; Parsons et al., 2012) which can propagate several hundred meters (Parsons et al., 2009, 2012). Individual G. hebraicum calls are more likely to be effective at ranges of up to around $100 \mathrm{~m}$ (assuming typical ambient noise levels of $80-90 \mathrm{~dB}$ re $1 \mu \mathrm{Pa}$ over the same bandwidth and spherical spreading as the maximum transmission loss). Given the likely number of calling fish, it is less probable that the calls are used as a long-range advertisement and more likely that they are involved in close-range mating behavior.

Calls from both fish displayed a broad range in SLs (11 and $24 \mathrm{~dB}$ re $1 \mu \mathrm{Pa}$ range for rms SL for the two fish, respectively) and peak frequencies (104 and169 Hz range, respectively). A possible source of variation in the SLs is the variation in range between fish and hydrophone. An estimate of $\pm 0.5 \mathrm{~m}$ was made for three standard deviations in the distribution of distances at which measurements were taken. This difference in source range would have a greatest impact, contributing approximately $9.5 \mathrm{~dB}$ to variation in SL, assuming spherical spreading as the only transmission loss. The remaining SL variation is not unusual in the wild. Parsons et al. (2012) determined $17 \mathrm{~dB}$ re $1 \mu \mathrm{Pa}$ confidence 

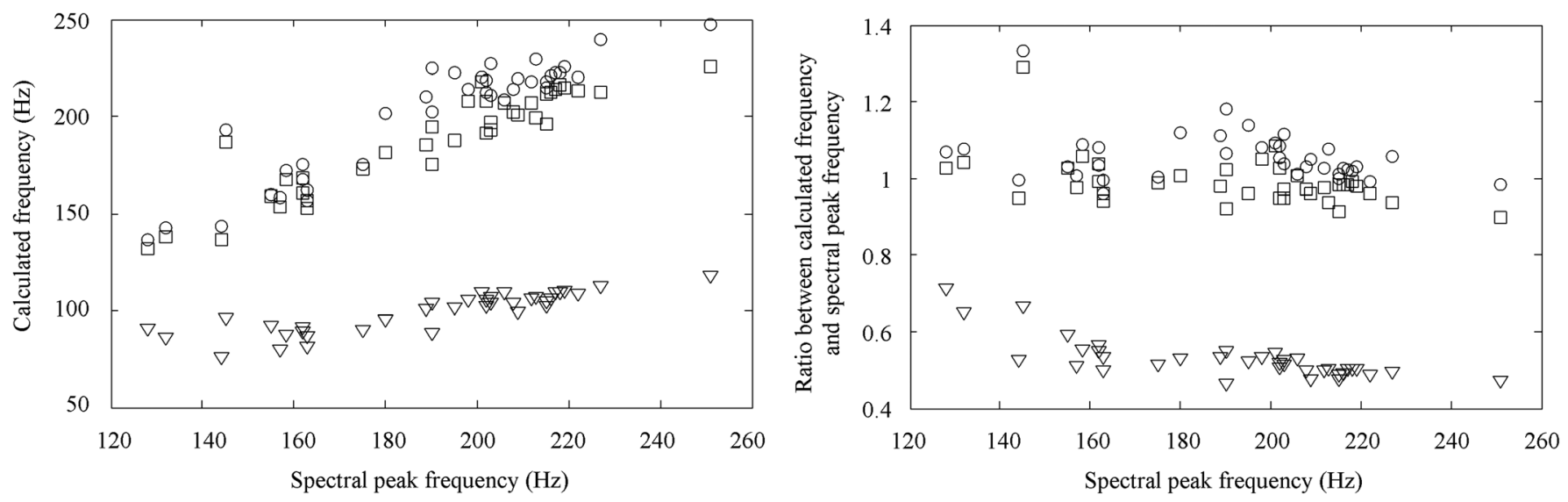

FIG. 7. Relationship between calculated frequency (left) and ratio between calculated and spectral peak frequency (right) and the spectral peak frequency of the first cycle (circles), second cycle (squares), and total duration (triangles) of individual pulses of calls where the peaks of cycles were free of surface reflections.

limits in SLs of a single A. japonicus at various ranges, while Lagardere and Mariani (2006) noted considerable differences in pressure amplitudes of consecutive pulses within single calls of Argyrosomus regius. Such variation has been noted in calls of other species as well (Nilsson, 2004). As call SLs are related not only to fish size, but also muscle tension among other factors (Sprague, 2000), it is conceivable that the fish is responsible for some of this variation in SL. As muscle tension also relates to peak frequency (Sprague, 2000; Rome, 2005), it follows that some of the variation in call frequency may also be attributed to differences in sonic muscle tension applied by the fish. Other factors likely to contribute to variations in estimated SL were the environment, changing fish depth, and surface reflections, not to mention the changes in fish behavior during capture, retrieval, and release. Connaughton et al. (2000) noted the relationship between the frequency of the second cycle in the pulse pressure wave and the peak frequency of the call.
A similar relationship was observed in this study; however, both the first and second cycle in the G. hebraicum calls here were similar to the spectral peak frequency of the pulse indicating a lack of damping compared with that of the weakfish.

While this study only had a sample of two fish, there were points of note with the difference in size between the fish. Here, the rms SLs of calls from the larger fish were greater than those of the smaller fish, while the spectral peak frequencies were lower. In other species, it has been shown that SL increases with size while peak frequency decreases (Connaughton et al., 2000), thus the observed differences were expected. In contrast, the maximum SELs in the larger fish were lower than the smaller fish suggesting that the pulse duration was longer (Parsons et al., 2012). This is in line with the lower peak frequencies in calls of the larger fish.

As the number of pulses in $G$. hebraicum calls increased, the maximum recorded SL decreased for calls of
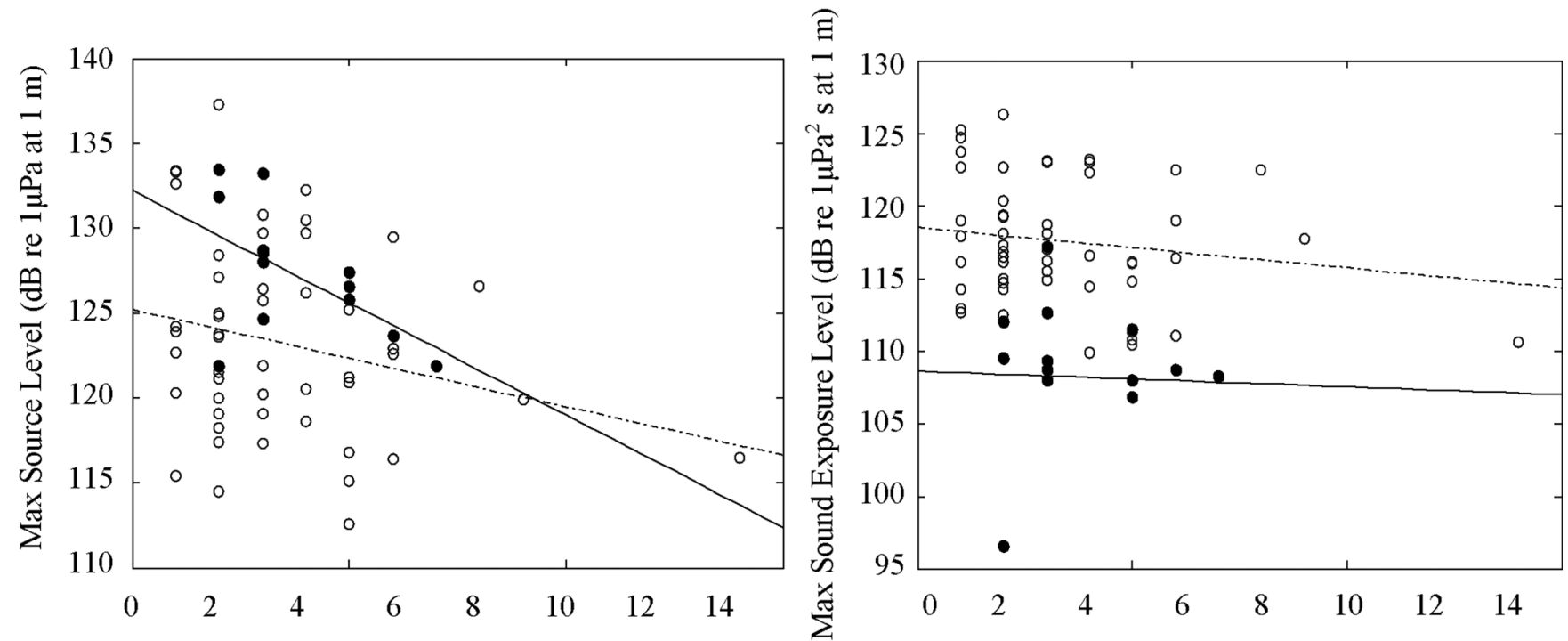

Number of pulses

FIG. 8. Distribution of maximum SLs (left) and SELs (right) against the number of pulses within the calls recorded from the 45 (filled circles) and 32 (empty circles) $\mathrm{cm}$ G. hebraicum. Continuous and dashed lines illustrate the trend in SL with increasing numbers of pulses within a call for fish 1 and fish 2 , respectively. 
both fish. Therefore, calls became quieter as more swimbladder pulses were used. This suggests that an increase in call duration causes muscle fatigue, therefore limiting the production of sounds of multiple pulses, as suggested for other species (Nilsson, 2004; Parsons, 2010; Mitchell et al., 2008). Amorim et al. (2002) reported that sound production does not appear to be a costly activity for $O$. tau at the whole body level, thus it is likely that in the two G. hebraicum recorded, their muscles did not possess the fitness to produce calls of many pulses. Whether this is similar for other G. hebraicum and if not, whether the differences provide information to the call recipient about the caller requires testing.

Many fish species, despite low call SLs, increase their call catchment area by calling en masse, numbering in the thousands of fish (McCauley, 2001). However, the small numbers of $G$. hebraicum groups observed by Mackie et al. (2009) suggest that today a chorus of G. hebraicum involving groups of hundreds to thousands of fish, similar to those of lekking species, where males group together first to attract females (Höglund and Alatalo, 1995), is unlikely. However, between December and March each year, G. hebraicum spawn along the Western Australian coast, most notably in waters off Cape Naturaliste, southwestern Australia (Mackie et al., 2009). Although exact locations of spawning may not be known, commercial fishers report significant catches in this area of spawning G. hebraicum (Mackie et al., 2009). It is possible that the numbers of $G$. hebraicum aggregating in this area are sufficient to produce a detectable chorus and studies are underway to locate and record such an event.

\section{CONCLUSIONS AND FUTURE WORK}

The ability of $G$. hebraicum to produce sound has been confirmed through an examination of physical characteristics and recording of sound directly from individual fish. It is necessary to determine the associated functions of calls to gain an understanding of whether they are made in relation to spawning or other behavior. There is the potential to use these identified calls to locate vocalizing G. hebraicum in the future, possibly to delimit sites where the fish aggregate and/or spawn. To investigate sound-related behavior further, an array of sea-noise loggers have been deployed at sites around southwestern Australia, where commercial fishers reportedly catch significant numbers of G. hebraicum, and also at sites near Augusta where juvenile G. hebraicum have been observed and sounds heard by researchers.

\section{ACKNOWLEDGMENTS}

The authors would like to acknowledge the Fisheries Research and Development Corporation (FRDC) for project support and funding, as well as the WA Department of Fisheries for logistical support and in-kind financial contribution. Grateful thanks go to Alex Hesp and Michael Mackie who reviewed the paper for the Department of Fisheries, Western Australia.

Amorim, M. C. P., McCracken, M. L., and Fine, M. L. (2002). "Metabolic costs of sound production in the oyster toadfish, Opsanus tau," Can. J. Zoology 80, 830-838.
Barimo, J. F., and Fine, M. L. (1998). "Relationship of swim-bladder shape to the directionality pattern of underwater sound in the oyster toadfish," Can. J. Zool. 76, 134-143.

Bartholomew, A., and Bohnsack, J. A. (2005). "A review of catch-andrelease angling mortality with implications for no-take reserves," Rev. Fish Biol. Fisher. 15, 129-154.

Cato, D. H. (1980). "Some unusual sounds of apparent biological origin responsible for sustained background noise in the Timor Sea," J. Acoust. Soc. Am. 68, 1056-1060.

Cato, D. H. (1998). "Simple methods of estimating source levels and locations of marine animal sounds," J. Acoust. Soc. Am. 104(3), 1667-1678.

Chiu, K. H., Wu, K. C., and Mok, H. K. (2006). "The swim bladder of Glaucosoma buergeri (Perciformes: Glaucosomatidae) and the histological and biochemical characteristic of its associated muscles," Conference on Bioacoustics-Related Research, Kaohsiung, Taiwan, December 6th, 2006.

Connaughton, M. A., Taylor, M. H., and Fine, M. L. (2000). "Effects of fish size and temperature on weakfish disturbance calls: Implications for the mechanism of sound generation," J Exp. Biol. 203, 1503-1512.

Fine, M. L., Winn, H. E., and Olla, B. L. (1977) "Communication in fishes," in How Animals Communicate, edited by T. A. Sebeok (Indiana University Press, Bloomington, IN), pp. 472-518.

Gannon, D. P. (2008). "Passive acoustic techniques in Fisheries Science: A review and prospectus" Trans. Am. Fish. Soc. 137, 638-656.

Hauser, M. D. (1996). The Evolution of Communication (MIT Press, Cambridge, MA), pp. 111-145.

Hesp, S. A., Potter, I. C., and Hall, N. G. (2002). "Age and size composition, growth rate, reproductive biology, and habitats of the West Australian dhufish (Glaucosoma hebraicum) and their relevance to the management of this species," Fishery Bulletin 100, 214-227.

Höglund, J., and Alatalo, R. V. (1995). Leks (Princeton University Press, Princeton, NJ), pp. 49-147.

Hutchins, B. and Swainston. R. (1986). Sea Fishes of Southern Australia. Complete Field Guide for Anglers and Divers (Swainston, Willagee, WA, Australia), pp. 1-180.

Kaatz, I. M. (2002). "Multiple sound producing mechanisms in teleost fishes and hypotheses regarding their behavioural significance," Bioacoustics 12, 230-233.

Lagardere, J. P., and Mariani, A. (2006). "Spawning sounds in the meagre Argyrosomus regius recorded in the Gironde Estuary, France," J. Fish Bio. 69, 1697-1702.

Lenanton, R., St John, J., Keay, I., Wakefield, C., Jackson, G., Wise, B., and Gaughan, D. (2009). "Spatial scales of exploitation among populations of demersal scalefish: Implications for management. Part 2: Stock structure and biology of two indicator species, West Australian dhufish (Glaucosoma hebraicum) and pink snapper (Pagrus auratus), in the West Coast Bioregion," Final Report to Fisheries Research and Development Corporation on Project No. 2003/052, Fisheries Research Report No. 174, Department of Fisheries, WA, pp. 1-187.

Locascio, J. V., and Mann, D. A. (2011). "Localization and source level estimates of black drum (Pogonias cromis) calls," J. Acoust. Soc. Am. 130(4), 1868-1879.

Mackie, M. C., McCauley, R. D., Gill, R. H., and Gaughan, D. J. (2009). "Management and monitoring of fish spawning aggregations within the west coast bio-region of Western Australia," Report no. 187, Final report to Fisheries Research and Development Corporation on Project No. 2004/ 051, Fisheries Research Report No. 163, Perth, pp. 1-243.

McCauley, R. D. (2001). "Biological sea noise in northern Australia: Patterns of fish calling," Ph.D. thesis, James Cook University of North Queensland, pp. 1-290.

McKay, R. J. (1997). "Pearl perches of the world," in FAO Species Catalogue (FAO, Rome), Vol. 17, pp. 1-26.

Mitchell, S. L., Poland, J., and Fine, M. L. (2008). "Does muscle fatigue limit advertisement calling in the oyster toadfish Opsanus tau," Anim. Behav. 76, 1011-1016.

Mok, H. K., Parmentier, E., Chiu, K. H., Tsai, K. E., Chiu, P. H., and Fine, M. L. (2011). "An intermediate in the evolution of superfast sonic muscle," Front. Zool. 8, 31-38.

Myrberg, A. A. J., and Spires, J. Y. (1972). "Sound discrimination by the bicolour damselfish (Eupomacentrus Partitus), " J. Exp. Biol. 57, 727-735.

Nilsson, J. (2004). "Acoustic behaviour of spawning cod (Gadus morhua)," Candidatus scientiarum thesis, University of Bergen, pp. 1-135.

Parsons, M. J. G. (2010). "Passive acoustic techniques for monitoring fish aggregations," in "An investigation into active and passive acoustic techniques to study aggregating fish species," Ph.D. thesis, Curtin University, pp. 131-297. 
Parsons, M. J. G., McCauley, R. D., Mackie, M., and Duncan, A. J., (2012) "In situ source levels of mulloway (Argyrosomus japonicus) calls," J. Acoust. Soc. Am. 132(5), 3559-3568.

Parsons, M. J. G., McCauley, R. D., Mackie, M. C., Siwabessy, P. J., and Duncan, A. J. (2009). "Localisation of an individual mulloway (Argyrosomus japonicus) within a spawning aggregation and their behavioural characteristics throughout a diel spawning period,’ ICES J. Mar. Sci. 66, 1007-1014.

Rome, L. C. (2005). "Principles of actuation in the muscular system of fish," IEEE J. Ocean. Eng. 30, 630-646.

Rountree, R. A., Gilmore, R. G., Goudey, C. A., Hawkins, A. D., Luczkovich, J. J., and Mann, D. A. (2006), "Listening to fish: Applications of passive acoustics to fisheries science," Fisheries 31, 433-446.

Sasaki, K., (2001). "Sciaenidae. Croakers (drums)," in FAO species identification guide for fishery purposes. The living marine resources of the Western Central Pacific. Volume 5. Bony fishes part 3 (Menidae to Pomacentridae), edited by K. E. Carpenter and V. H. Niem (FAO, Rome), pp. 2791-3380, 3117-3174.

Silberschneider, V., Gray, C. A., and Stewart, J. (2009). “Age, growth, maturity and the overfishing of the iconic sciaenid, Argyrosomus japonicus, in south-eastern, Australia," Fish. Res. 95, 220-229.

Slabbekoorn, H., Bouton, N., van Opzeeland, I., Coers, A., ten Cate1, C., and Popper, A. N. (2010). "A noisy spring: The impact of globally rising underwater sound levels on fish," Trends Ecol. Evol. 25, 419-427.

Southall, B. L., Bowles, A. E., Ellison, W. T., Finneran, J. J., Gentry, R. L., Greene, C. R., Jr., Kastak, D., Ketten, D. R., Miller, J. H., Nachtigall, P.
E., Richardson, W. J., Thomas, J. A., and Tyack., P. L. (2007). "Marine mammal noise exposure criteria: Initial Scientific Recommendations," Aquat. Mamm. 33, 415-477.

Sprague, M. W. (2000). "The single sonic twitch model for the sound production mechanism in the weakfish, Cynoscion regalis," J. Acoust. Soc. Am. 108, 2430-2437.

Sprague, M. W., and Luczkovich, J. J. (2004). "Measurement of an individual silver perch Bairdiella chrysoura sound pressure level in a field recording," J. Acoust. Soc. Am. 116, 3186-3191.

St John, J., and Syers, C. J. (2005). "Mortality of the demersal West Australian dhufish, Glaucosoma hebraicum (Richardson 1845) following catch and release: The influence of capture depth, venting and hook type," Fish. Res. 76, 106-116.

Urick, R. J. (1983). Principles of Underwater Sound, 3rd ed. (MacGrawHill, New York), pp. 1-451.

Winn, H. E. (1964). "The Biological Significance of Fish Sounds," in Marine Bioacoustics, edited by W. N. Tavolga (Pergamon, Sydney), Vol. 2, pp. 213-231.

Wise, B. S., St John, J., and Lenanton, R. C. (2007). "Spatial scales of exploitation among populations of demersal scalefish: Implications for management. Part 1: Stock status of the key indicator species for the demersal scalefish fishery in the West Coast Bioregion," Final report to Fisheries Research and Development Corporation on Project No. 2003/052. Fisheries Research Report No. 163, Department of Fisheries, Western Australia, pp. 1-130. 